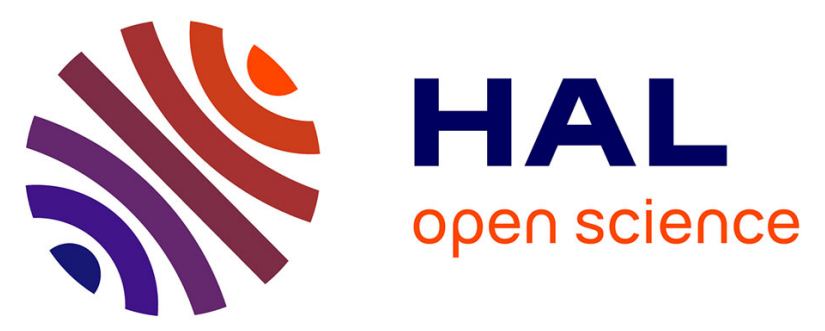

\title{
Socioeconomic differences in fruit and vegetable consumption among middle-aged French adults: adherence to the 5 a day recommendation
}

Carla Estaquio, Nathalie Druesne Pecollo, Paule Latino-Martel, Luc Dauchet, Serge Hercberg, Sandrine Bertrais

\section{To cite this version:}

Carla Estaquio, Nathalie Druesne Pecollo, Paule Latino-Martel, Luc Dauchet, Serge Hercberg, et al.. Socioeconomic differences in fruit and vegetable consumption among middle-aged French adults: adherence to the 5 a day recommendation. Journal of The American Dietetic Association, 2008, 108 (12), pp.2021-2030. 10.1016/j.jada.2008.09.011 . hal-02663362

\section{HAL Id: hal-02663362 \\ https://hal.inrae.fr/hal-02663362}

Submitted on 31 May 2020

HAL is a multi-disciplinary open access archive for the deposit and dissemination of scientific research documents, whether they are published or not. The documents may come from teaching and research institutions in France or abroad, or from public or private research centers.
L'archive ouverte pluridisciplinaire $\mathbf{H A L}$, est destinée au dépôt et à la diffusion de documents scientifiques de niveau recherche, publiés ou non, émanant des établissements d'enseignement et de recherche français ou étrangers, des laboratoires publics ou privés. 


\section{Current Research}

\section{Socioeconomic Differences in Fruit and Vegetable Consumption among Middle-Aged French Adults: Adherence to the 5 A Day Recommendation}

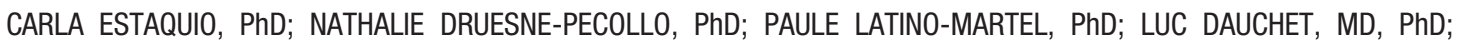

SERGE HERCBERG, MD, PhD; SANDRINE BERTRAIS, PhD

\section{ABSTRACT}

Background Numerous studies support the protective effect of high fruit and vegetable consumption on chronic disease risk, mainly against cancer and cardiovascular diseases. The increase of fruit and vegetable intake has become a public health priority in many countries.

Objective The aim of the study was to investigate the relationships of socioeconomic, demographic, and behavioral factors with both quantity and variety of fruit and vegetable consumption.

Design/subjects Fruit and vegetable intake was assessed using repeated 24-hour dietary records collected during a 2-year period from 4,282 French subjects (2,373 men and 1,909 women), aged 45 to 62 years, who participated in a large prospective study.

Statistical analysis Both education level and occupation categories were used as socioeconomic indicators. Logistic regression models were applied to assess factors related to meeting the $5 \mathrm{~A}$ Day fruit and vegetable recommendation. Covariance analyses were performed to compare the fruit and vegetable variety scores and the contributions of fruit and vegetables to the total daily diet cost across socioeconomic indicators within each sex.

C. Estaquio and S. Bertrais are epidemiologists, Department of Nutritional Epidemiology, French Institute of Health and Medical Research, Bobigny, France. $N$.

Druesne-Pecollo is a scientific attaché and P. LatinoMartel is a senior scientist, Department of Nutritional Epidemiology, French National Institute for Agricultural Research, Bobigny, France. L. Dauchet is assistant professor of epidemiology and public health, University Hospital of Lille, France. S. Hercberg is a nutritionist and full professor and head of the department, Department of Nutritional Epidemiology, French Institute of Health and Medical Research, Bobigny, France.

Address correspondence to: Carla Estaquio, PhD, UREN-UMR INSERM/INRA/CNAM, Paris 13, Centre de Recherche en Nutrition Humaine d'Ile-de-France, 74 rue Marcel Cachin, 93017 Bobigny Cedex, France.

E-mail: c.estaquio@uren.smbh.univ-paris13.fr

Manuscript accepted: May 23, 2008.

Copyright $(02008$ by the American Dietetic

Association.

0002-8223/08/10812-0004\$34.00/0

doi: 10.1016/j.jada.2008.09.011
Results Meeting the 5 A Day recommendation was more likely in subjects aged 50 years and older, higher education levels, nonsmokers, moderate alcohol drinkers and in women engaging in regular physical activity. The odds ratio (95\% confidence interval) for the lower vs higher education level was 0.70 (0.54 to 0.92$)$ in men and 0.65 (0.48 to 0.85 ) in women. No significant difference was observed between occupation categories. A positive relationship between vegetable variety and education level was found in both sexes. Fruit variety was positively associated with both education and occupation categories, but only in men. The contribution of fruits to the total daily diet cost increased with occupation $(P<0.02)$ and education $(P<0.0001)$ in men, but decreased with occupation in women $(P<0.05)$.

Conclusions Although cost constraints may explain the lower fruit and vegetable intake in lower socioeconomic groups, the relative influence of budgetary resources, nutrition knowledge, and social and environmental barriers in socioeconomic disparities need further investigation. $J$ Am Diet Assoc. 2008;108:2021-2030.

igh consumption of fruits and vegetables has been suggested to be associated with a lower mortality risk (1) and a reduced incidence of many chronic diseases such as cardiovascular disease (2), stroke (3), and certain cancers (4). A recent report of the World Health Organization stated that there is convincing evidence that fruit and vegetable consumption also decreases risk of diabetes and obesity (5). The report recommended a minimum intake of $400 \mathrm{~g}$ fruits and vegetables per day.

Increasing fruit and vegetable intake by the general population has become a public health priority in many countries (4-6), with government agencies around the world asserting that everyone should eat at least five servings of fruit and vegetables daily (ie, $\geq 400 \mathrm{~g} /$ day) (5). The Healthy People 2010 health objectives in the United States include increasing to $75 \%$ the number of people who eat at least two daily servings of fruit and increasing to $50 \%$ the number of those who eat at least three daily servings of vegetables. In France, fruit and vegetables are targeted by one of the nine nutrition priority goals specified in the Programme National Nutrition Santé for the 2001-2010 period. More precisely, the objective is to reduce the frequency of low consumers $(<3.5$ servings per day [7]) by $25 \%$. As in several other countries, a national 
campaign has been launched to promote the consumption of at least five servings of fruits and vegetables per day.

Identifying the correlates of fruit and vegetable consumption is a first step that may help health policy makers target at-risk populations and guide the development of specific actions to improve fruit and vegetable intake by low consumers. According to previous studies, socioeconomic factors like occupation categories and education level are important determinants of low fruit and vegetable intake $(8,9)$. Compared to the United States and other European countries (8-10), there are few data regarding the consumption of fruit and vegetables and its relation with socioeconomic status in France.

The aim of this study was to investigate relationships of socioeconomic, demographic, and behavior factors with both quantity and variety of fruit and vegetable consumption in a sample of middle-aged French subjects. This study also quantified the contribution of fruit and vegetables to total diet cost according to socioeconomic status. The hypothesis was that due to budgetary constraints people with low education and from low occupation categories have lower fruit and vegetables intake in terms of both consumed quantity and variety.

\section{MATERIALS AND METHODS \\ Study Population}

This study was conducted using data from the SUpplémentation en VItamines Minéraux et AntioXydants (SU.VI.MAX) cohort, a large sample of middle-aged adults living all over French territory. The design, methods, and rationale of the SU.VI.MAX study have been described elsewhere (11). The SU.VI.MAX study was initially designed as a randomized, double blind, placebocontrolled, primary prevention trial to test the efficacy of daily supplementation with antioxidant vitamins and minerals at nutritional doses in reducing the incidence of ischemic heart disease and cancers. A total of 13,017 subjects $(5,141$ men aged 45 to 62 years; 7,876 women aged 35 to 62 years) were included in 1994-1995 for a planned follow-up of 8 years. The SU.VI.MAX study was approved by the Ethical Committee for Studies with Human Subjects at the Paris-Cochin Hospital (CCPPRB No. 706) and the Commission Nationale Informatique et Liberté (CNIL No. 334641).

For our analyses, the only subjects included were those aged 45 to 62 years who completed at least six 24-hour dietary records during the first 2 years of follow-up and with available data for all sociodemographic and behavioral characteristics. Furthermore, to take into account seasonal variations in fruit and vegetable consumption (12), the study sample was restricted to subjects having at least two 24-hour dietary records in the autumn-winter period (November to April) and at least two 24-hour dietary records in the spring-summer period (May to October).

\section{Dietary Assessment}

Dietary data were collected using the Minitel Telematic Network. The Minitel is a small terminal that was widely used as an adjunct to the telephone in France at the beginning of the SU.VI.MAX study. Participants were invited to transmit dietary data every 2 months. At enrollment, they received a scheduled calendar of 24-hour dietary data recording and a tiny central processing unit specifically developed for the study containing specialized software that allowed subjects to fill out the computerized dietary record off-line and to transmit data during brief telephone connections. The 24-hour records were distributed randomly for 2 weekend days and 4 weekdays per year, so that each day of the week was covered in all seasons for the mean intake of each participant. Diet has been shown to be very stable across the years in this cohort so diet measured over the first 2 years was considered to be representative of usual diet. Subjects were assisted by the conversational features of the software and an instruction guide for codification of foods, including photographs to facilitate estimation of portion size. This manual includes photographs of more than 250 foods (corresponding to 1,000 generic foods) represented in three different portion sizes. Along with the two intermediate and two extreme quantities, there are seven choices of amounts. Edible portions corresponding to each food were previously validated in a pilot study (13).

The nutritional values of the diet were estimated using a recently published French food composition table (14). This database was completed by the unit cost of each food, based on the mean retail prices in France in 1997, obtained from marketing research, from the French National Institute of Statistics and Economic Studies, and from supermarket Web sites. To account for potential seasonal and weekly variations, all values reported here are based on the average dietary intakes of each subject including beverages.

The fruit and vegetable group includes fruits, vegetables, $100 \%$ fruit or vegetable juices, and mixed foods whose ingredients contain fruits or vegetables. To comply with French guidelines, dried fruits, potatoes, and legumes were not included in the fruit and vegetable group (6). French recipes validated by food and nutrition professionals were used to assess the amounts consumed from mixed foods. To assess the compliance with fruit and vegetable recommendations (at least five servings per day), one serving was defined as $80 \mathrm{~g}$ fruit and vegetable (ie, a common portion size described in the literature) $(15,16)$. Furthermore, fruit and vegetable were classified using the International Agency for Research on Cancer classification (4) adapted to French dietary habits (see the Figure). Methodology used to calculate fruit or vegetable variety scores was similar to those described by Giskes and colleagues (17). Separate scores were calculated for fruits and vegetables. Variety was measured as the number of different types of fruits/vegetables consumed. Each type of fruits/vegetables consumed was given a score of 1 . Mixed dishes were given a score of 2 when the recipe contained at least two types of fruits/ vegetables.

\section{Assessment of Sociodemographic and Behavior Characteristics}

At enrollment subjects were asked to fill in a questionnaire to provide sociodemographic and lifestyle information. Level of education was coded in three categories: elementary school, secondary school (junior and high school), university, or equivalent. Occupation categories were used as proxy for income ranges because direct 


\begin{tabular}{|ll|}
\hline Fruit & \\
Apple, pear, and other pome fruits & Apple, medlar, pear \\
Citrus fruits & Clementine, grapefruit (yellow/pink), lemon, mandarin orange, orange \\
Grapes & Grapes (red/green) \\
Berries & Blackberry, blackcurrant, gooseberry, huckleberry, raspberry, redcurrant, strawberry \\
Stone fruits & Apricot, cherry, nectarine, peach, plum \\
Melon & Cantaloupe (muskmelon), watermelon \\
Banana & Banana \\
Other tropical fruits & Fig, kiwi fruit, lychee, mango, papaya, passion fruit, persimmon, pineapple, pomegranate \\
Fruit juices & Apple juice, grape juice, grapefruit juice, lemon juice, orange juice, pineapple juice \\
Vegetables & \\
Green salads & Chicory, corn salad, curly endive, dandelion, French endive, lettuce, mixed green salad, watercress \\
Leafy vegetables & Brussels sprout, cabbage (green/red/white), pickled cabbage, spinach \\
Fruits used as vegetables & Avocado, cherry tomato, cucumber, eggplant, pepper (green, yellow, red), pumpkin, tomato, tomato \\
& puree, tomato sauce, zucchini \\
Root vegetables & Beet (beetroot), carrot, celeriac (celery root), radish, salsify, turnip \\
Green beans and peas & Green pea, green bean, mixture of diced vegetables \\
Bulb and stem vegetables & Asparagus, cardoon, celery, fennel bulb, garlic, heart of palm, leek, onion, rhubarb, shallot, scallion \\
Flowering vegetables & Artichoke, broccoli, cauliflower \\
Mushrooms & Mushrooms \\
Sprouts & Bean sprout \\
Vegetable juices & Carrot juice, tomato juice, mixed vegetable juices \\
\end{tabular}

Figure. Classification of fruits and vegetables according to French dietary habits. Methodology adapted from reference (4).

measure of material resources was not available. In France, subjects are generally unwilling to provide their income. The official French classification (18) was used to classify subjects into four occupation categories according to their self-reported occupation or last occupation if they were retired or unemployed. The incomes of these different occupation categories are generally quite close for intermediate professions, employees, farmers, and manual workers and higher for managerial staff.

The location of residence was classified in two categories (urban/rural) according to the definition of the French National Institute of Statistics and Economics Studies, which is based on both population density and economic activity of the area corresponding to each subject's zip code (19). Smoking status was categorized as current, former, or never. Overall level of habitual physical activity was assessed using the following questions: "Do you get regular physical activity (transportation, work, and leisure combined): yes/no? If yes, is it equivalent to at least 1 hour of walking per day?" Responses were coded in three categories (irregular, $<1$ hour of walking per day, $\geq 1$ hour of walking per day) (20). Alcohol intake was estimated in grams of alcohol per day, from a short validated semiquantitative dietary questionnaire (21).

\section{Statistical Analyses}

Data were analyzed by gender to account for differences in dietary behaviors between men and women. All statistical analyses were performed using SAS software (version 8.2, 2001, SAS Institute Inc, Cary, NC). Descriptive results are reported as percentages or mean \pm standard deviation. The Student $t$ test and $\chi^{2}$ test were used to compare sexes, as appropriate. Logistic regression models were applied to assess factors related to meeting the recommendation to consume five servings of fruits and vegetables per day. Multivariate models included age, education level, occupation categories, marital status, household location, smoking status, physical activity categories, alcohol consumption, and total daily energy intakes. Adjusted odds ratios and their 95\% confidence intervals are reported. Covariance analyses were performed to compare average fruit and vegetable variety scores, expenses to eat fruit and vegetables, and contributions of fruit and vegetables to the total cost of the daily diet, across socioeconomic status (ie, education level and occupation categories) within each sex after adjustment for total energy intake. Global and linear trend tests were performed. Because of skewed distribution of variety score values, comparisons were based on squareroot transformed data. For all analyses, the significance level was set at $P<0.05$.

\section{RESULTS}

Table 1 summarizes the general characteristics of the sub-

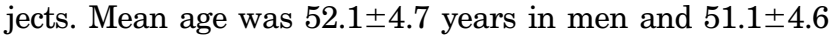
years in women $(P<0.0001)$. All sociodemographic and behavior factors significantly differed between sexes. More than $83 \%$ of men and women lived in an urban area $(P<0.35$ for sex difference).

\section{Consumption of Fruit and Vegetables}

Mean daily energy intakes were $2,431 \pm 537 \mathrm{kcal} /$ day in men and $1,775 \pm 421 \mathrm{kcal} /$ day in women $(P<0.0001)$. As shown in Table 1, more than $50 \%$ of men and women consumed at least five servings of fruit and vegetables per day (ie. $\geq 400 \mathrm{~g}$ per day). After controlling for total energy intakes, women had higher consumption than men for both fruits and vegetables. However, the contributions of 
Table 1. Basic characteristics of selected participants in the Supplémentation en Vitamines et Minéraux Antioxydants study

\begin{tabular}{|c|c|c|c|c|}
\hline Characteristic & \multirow{2}{*}{\multicolumn{2}{|c|}{$\begin{array}{l}\text { Men } \\
(n=2,373)\end{array}$}} & \multirow{2}{*}{\multicolumn{2}{|c|}{$\begin{array}{l}\text { Women } \\
(n=1,909)\end{array}$}} \\
\hline Sociodemographic & & & & \\
\hline Age group $(y)^{a}$ & \multicolumn{4}{|c|}{$n \%$} \\
\hline $45-49$ & 866 & 36.5 & 860 & 45.1 \\
\hline $50-54$ & 727 & 30.6 & 560 & 29.3 \\
\hline \multirow{2}{*}{\multicolumn{5}{|c|}{ Education level ${ }^{\text {a }}$}} \\
\hline & & & & \\
\hline University or equivalent & 959 & 40.4 & 676 & 35.4 \\
\hline Secondary school & 843 & 35.5 & 834 & 43.7 \\
\hline Elementary school & 571 & 24.1 & 399 & 20.9 \\
\hline \multicolumn{5}{|l|}{ Occupation categories ${ }^{\mathrm{ab}}$} \\
\hline Managerial staff & 1,007 & 42.4 & 355 & 18.6 \\
\hline \multicolumn{4}{|l|}{ Intermediate professions, } & 74.4 \\
\hline Farmers, self-employed & 127 & 5.4 & 87 & 4.6 \\
\hline Manual workers & 165 & 7.0 & 47 & 2.5 \\
\hline \multicolumn{5}{|l|}{ Marital status ${ }^{\mathbf{a}}$} \\
\hline Living alone & 224 & 9.4 & 360 & 18.9 \\
\hline Cohabiting & 2,149 & 90.6 & 1,549 & 81.7 \\
\hline \multicolumn{5}{|l|}{ Household location ${ }^{\mathrm{c}}$} \\
\hline Urban & 1,989 & 83.8 & 1,620 & 84.9 \\
\hline Rural & 384 & 16.2 & 289 & 15.1 \\
\hline \multicolumn{5}{|l|}{ Smoking status ${ }^{a}$} \\
\hline Nonsmokers/former smokers & 2,056 & 86.7 & 1,696 & 88.8 \\
\hline \multicolumn{5}{|l|}{ Physical activity ${ }^{\text {ad }}$} \\
\hline Irregular & 550 & 23.2 & 473 & 24.8 \\
\hline of walking & 586 & 24.7 & 671 & 35.2 \\
\hline$\geq 1 \mathrm{~h} / \mathrm{d}$ of walking & 1,237 & 52.1 & 765 & 40.0 \\
\hline \multirow{2}{*}{\multicolumn{5}{|c|}{$\begin{array}{l}\text { Dietary intake } \\
\text { Alcohol consumption } \\
(\mathrm{g} / \mathrm{d})^{\mathrm{ae}}\end{array}$}} \\
\hline & & & & \\
\hline$<20 \mathrm{~g} / \mathrm{d}$ & 821 & 34.6 & 1,763 & 92.4 \\
\hline$\geq 20 \mathrm{~g}$ & 1,552 & 65.4 & 146 & 7.6 \\
\hline \multirow{3}{*}{$\begin{array}{l}\geq 5 \text { fruits and vegetables } \\
\text { per day }\end{array}$} & \multirow{2}{*}{\multicolumn{2}{|c|}{$54 \%$}} & \multirow{2}{*}{\multicolumn{2}{|c|}{$53 \%$}} \\
\hline & & & & \\
\hline & \multicolumn{4}{|c|}{$\leftarrow$ mean \pm standard deviation $\longrightarrow$} \\
\hline Energy intake $(g / d)^{\text {af }}$ & $2,431.0$ & 537 & $1,775.0 \pm$ & 421 \\
\hline \multicolumn{5}{|l|}{ Fruits and vegetables } \\
\hline \multirow{2}{*}{\multicolumn{3}{|c|}{$\begin{array}{l}\text { Fruits }(\mathbf{g} / \mathbf{d})^{\mathbf{a g}} \\
\text { Apple, pear, and other pome }\end{array}$}} & $\begin{array}{l}492.4- \\
266.4 \pm\end{array}$ & $\begin{array}{l}-119.0 \\
119.0\end{array}$ \\
\hline & & & & \\
\hline fruits (\% of fruit intakes) $)^{\mathrm{a}}$ & \multicolumn{2}{|c|}{$33.8 \pm 21.4$} & $31.2=$ & $=18.3$ \\
\hline Citrus fruits (\% of fruit & & & & \\
\hline intakes) $^{\mathrm{a}}$ & 10.9 & 12.6 & $12.7=$ & $=11.0$ \\
\hline Grapes (\% of fruit intakes) & 4.5 & 8.6 & $4.1=$ & $=6.8$ \\
\hline Berries (\% of fruit intakes) ${ }^{a}$ & 8.5 & 10.2 & $9.5=$ & $=10.2$ \\
\hline Stone fruits (\% of fruit & & & & \\
\hline intakes) ${ }^{\mathrm{a}}$ & 9.1 & 11.1 & $9.9=$ & \\
\hline Melon (\% of fruit intakes) & 5.3 & 9.3 & $5.5=$ & 8.8 \\
\hline Banana ( $\%$ of fruit intakes $)^{\mathrm{a}}$ & 5.6 & 9.6 & $4.1=$ & 6.7 \\
\hline Other tropical fruits (\% of fruit & & & & \\
\hline intakes) & 9.3 & 11.9 & & 0.6 \\
\hline Fruit juices (\% of fruit intakes) & 15.4 & 20.3 & $15.0=$ & $=18.5$ \\
\hline
\end{tabular}

\begin{tabular}{|c|c|c|}
\hline Characteristic & \multirow{2}{*}{$\begin{array}{l}\text { Men } \\
(n=2,373)\end{array}$} & \multirow{2}{*}{$\begin{array}{l}\text { Women } \\
(n=1,909)\end{array}$} \\
\hline Sociodemographic & & \\
\hline $\begin{array}{l}\text { Variety score (\% of fruit } \\
\text { intakes) }\end{array}$ & $2.1 \pm 0.5$ & $2.4 \pm 0.5$ \\
\hline Vegetables (g/day) ${ }^{\text {ag }}$ & $196.1 \pm 89.8$ & $226.0 \pm 83.6$ \\
\hline $\begin{array}{l}\text { Green salads (\% of } \\
\text { vegetable intakes) }\end{array}$ & $14.2 \pm 9.8$ & $14.3 \pm 9.1$ \\
\hline $\begin{array}{l}\text { Leafy vegetables (\% of } \\
\text { vegetable intakes) }\end{array}$ & $7.8 \pm 8.4$ & $8.3 \pm 8.9$ \\
\hline $\begin{array}{l}\text { Fruits used as vegetables } \\
\text { ( } \% \text { of vegetable intakes) }\end{array}$ & $26.3 \pm 17.8$ & $25.7 \pm 13.1$ \\
\hline $\begin{array}{l}\text { Root vegetables (\% of } \\
\text { vegetable intakes) }\end{array}$ & $19.5 \pm 11.0$ & $19.4 \pm 10.4$ \\
\hline $\begin{array}{l}\text { Green beans and peas (\% of } \\
\text { vegetable intakes) }\end{array}$ & $13.4 \pm 10.6$ & $13.1 \pm 10.0$ \\
\hline $\begin{array}{l}\text { Bulb and stem vegetables } \\
\text { (\% of vegetable intakes) }\end{array}$ & $9.6 \pm 6.6$ & $9.2 \pm 6.2$ \\
\hline $\begin{array}{l}\text { intakes) }^{\mathrm{a}} \\
\text { Sprouts (\% of vegetable }\end{array}$ & $4.6 \pm 5.8$ & $3.8 \pm 4.5$ \\
\hline intakes) & $0.4 \pm 1.8$ & $0.4 \pm 1.5$ \\
\hline $\begin{array}{l}\text { Vegetable juices (\% of } \\
\text { vegetable intakes) }\end{array}$ & $0.3 \pm 2.2$ & $0.4 \pm 3.2$ \\
\hline $\begin{array}{l}\text { Variety score (\% of } \\
\text { vegetable intakes) }^{\text {ah }}\end{array}$ & $1.9 \pm 0.3$ & $2.1 \pm 0.3$ \\
\hline
\end{tabular}

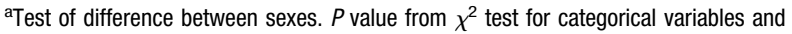
from Student $t$ test for continuous variables $<0.05$.

${ }^{\mathrm{b}}$ The official French classification (18) was used to classify subjects into four occupation categories according to self-reported occupation or last occupation if subject was retired or unemployed. The incomes of these different occupation categories are generally quite close for intermediate professions, employees, farmers, and manual workers and higher for the managerial staff.

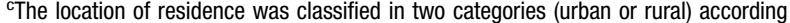
to the definition of the French National Institute of Statistics and Economics Studies, which is based on both population density and economic activity of the area corresponding to each subject's zip code (19).

${ }^{\mathrm{d}}$ The overall level of habitual physical activity was assessed using the following questions: "Do you get regular physical activity (transportation, work, and leisure combined): yes/no? If yes, is it equivalent to at least 1 hour of walking per day?" (20). Responses were coded in three categories.

eAlcohol intake was estimated in grams of alcohol per day, from a short validated semiquantitative dietary questionnaire (21).

fMean energy intakes estimated from repeated 24-hour dietary records collected during the 1995-1997 period.

${ }^{9}$ Adjusted for total daily energy intakes.

hSeparate variety scores were calculated for fruits and vegetables. Methodology used was similar to those described by Giskes and colleagues (17). Variety was measured as the number of different types of fruits/vegetables consumed. Each variety of fruits/vegetables consumed was given a score of 1 . Mixed dishes were given a score of 2 when the recipe contained at least two types of fruits/vegetables.

fruit and vegetable groups to total fruit and vegetable intake and the fruit and vegetable variety scores were very similar in both sexes (Table 1). Apple, pear, and other pome fruits; fruit juices; and citrus fruits (eg, orange and grapefruit) were the most consumed. Fruits used as vegetables (eg, tomato and cucumber) $(>25 \%)$, root vegetables $(>19 \%)$, green salads $(>14 \%)$, and green 
beans and peas $(>13 \%)$ were the major contributors to total vegetable intake.

\section{Intake of Composite Foods in Daily Fruit and Vegetable Consumption}

The mean intake of vegetables from composite foods was around $50 \mathrm{~g} / \mathrm{day}$, which represents $25 \%$ of total vegetable consumption. For fruit, composite foods were a less important contributor, at $20 \mathrm{~g} /$ day (9\% to $10 \%$ of total fruit intake). Fruit juices represented 40 g/day (20\% of total fruit intake).

\section{Meeting the 5 A Day Recommendation}

Results from univariate associations showed that, in both sexes, the percentages of subjects who consumed at least five servings per day increased with age and education level (Table 2). Borderline significant differences between occupation categories were found in men $(P<0.06)$. In both sexes, achieving the fruit and vegetable recommendation was negatively related to smoking status and positively to physical activity. A negative association was also observed with alcohol consumption, although only significant in men. No relationship was found with household location and marital status. In multivariate analyses, occupation categories in both sexes, and physical activity in men, were no longer related to fruit and vegetable intakes. Marital status was weakly associated with achieving recommended levels in men $(P=0.07)$.

\section{Variety Score}

Older subjects had higher vegetable variety scores in both sexes (Table 2). In contrast, no difference in fruit variety was observed between age groups. Fruit variety scores significantly increased with both education level and occupation categories in men, whereas vegetable variety score was positively associated with education in both sexes. Moreover, being married/living with a partner was associated with a higher fruit variety in women, and a higher vegetable variety in both men and women. Fruit variety was also associated with a more healthful lifestyle, including nonsmoking in both sexes, and low alcohol consumption and regular physical activity in men. Vegetable variety was inversely related to smoking status in men.

\section{Contribution of Fruit and Vegetables to Total Cost of Daily Diet}

Mean total cost of daily diet was $€ 6.92 \pm 1.8$ in men and $€ 5.36 \pm 1.5$ in women (Table 3 ). Managerial staff had more expensive diets than farmers/self-employed or manual workers in men, whereas both occupation and education were positively associated with total daily diet cost in women. The contribution of fruit and vegetable to the total diet cost was $16 \%$ of total diet cost (€1.09) and $20 \%$ $(€ 1.05)$, respectively, in men and women. Significant differences were found in men for education (mainly due to the contribution of fruits), whereas in women an association was found for occupation categories. In men, managerial staff and intermediate professions had the highest fruit cost contribution compared to manual workers (Table 3). In contrast, in women, managerial staff had the lowest fruit and vegetable contribution to total daily diet cost.

\section{Contribution of Fruit and Vegetable Categories to Total Cost of Daily Diet}

Analyses of the relationship between the two indicators of socioeconomic status (ie, occupation and education) and the various fruit and vegetable groups showed that the contribution of apple, pear, and other pome fruits to fruit expenses decreased with increasing education in women (Table 4). In both sexes, less-educated subjects spent more money to eat tropical fruits (other than banana). The contributions of fruit juices to daily fruit cost increased with education in both sexes and with occupation categories in men. A positive association with education was also observed for the contribution of fruits used as vegetables and green salads to vegetable cost, in women. Conversely, the contributions of root vegetables, green beans and peas, bulb, and stem vegetables to daily vegetable cost decreased with education. Occupation and education categories were positively related to green salad cost contribution only in women. No vegetable categories differed significantly according to education and occupation in men.

\section{DISCUSSION}

In this study, achieving the 5 A Day fruit and vegetable recommendation was positively related to education level in both sexes. Older subjects, nonsmokers, and moderate alcohol drinkers were more likely to meet fruit and vegetable recommendations. In women, a positive relationship between fruit and vegetable consumption and physical activity level was also observed. No association was found with occupation categories, after adjustment for education, sociodemographic, and behavior characteristics. Variety scores increased with education level for fruits and vegetables in men and only for vegetables in women. Occupation categories were positively associated with fruit variety in men. Contribution of fruit and vegetable to total daily diet cost also differed between socioeconomic groups with some sex-specific relationships.

\section{Intake of Composite Foods in Daily Fruit and Vegetable Consumption}

Most studies do not take into account composite foods and fruit juices, although composite foods are an important sources of fruit and vegetable intake. In our study, the results demonstrate that composite foods and fruit juices should be included when estimating fruit and vegetable intakes to avoid bias in estimates of intake, as mentioned elsewhere (22). It is interesting to note that the higher consumption of fruit and vegetable found for managerial and intermediate professions vs manual workers was due to the higher consumption of fruit juices. This result was also found among British adults (23).

\section{Socioeconomic Status and Adherence to the $5 \mathrm{~A}$ Day Recommendation}

The observed relationship between adherence to the $5 \mathrm{~A}$ Day recommendation and education level is consistent 
Table 2. 5 A Day consumption and variety score, in both sexes, according to sociodemographic and behavior characteristics ${ }^{\text {a }}$

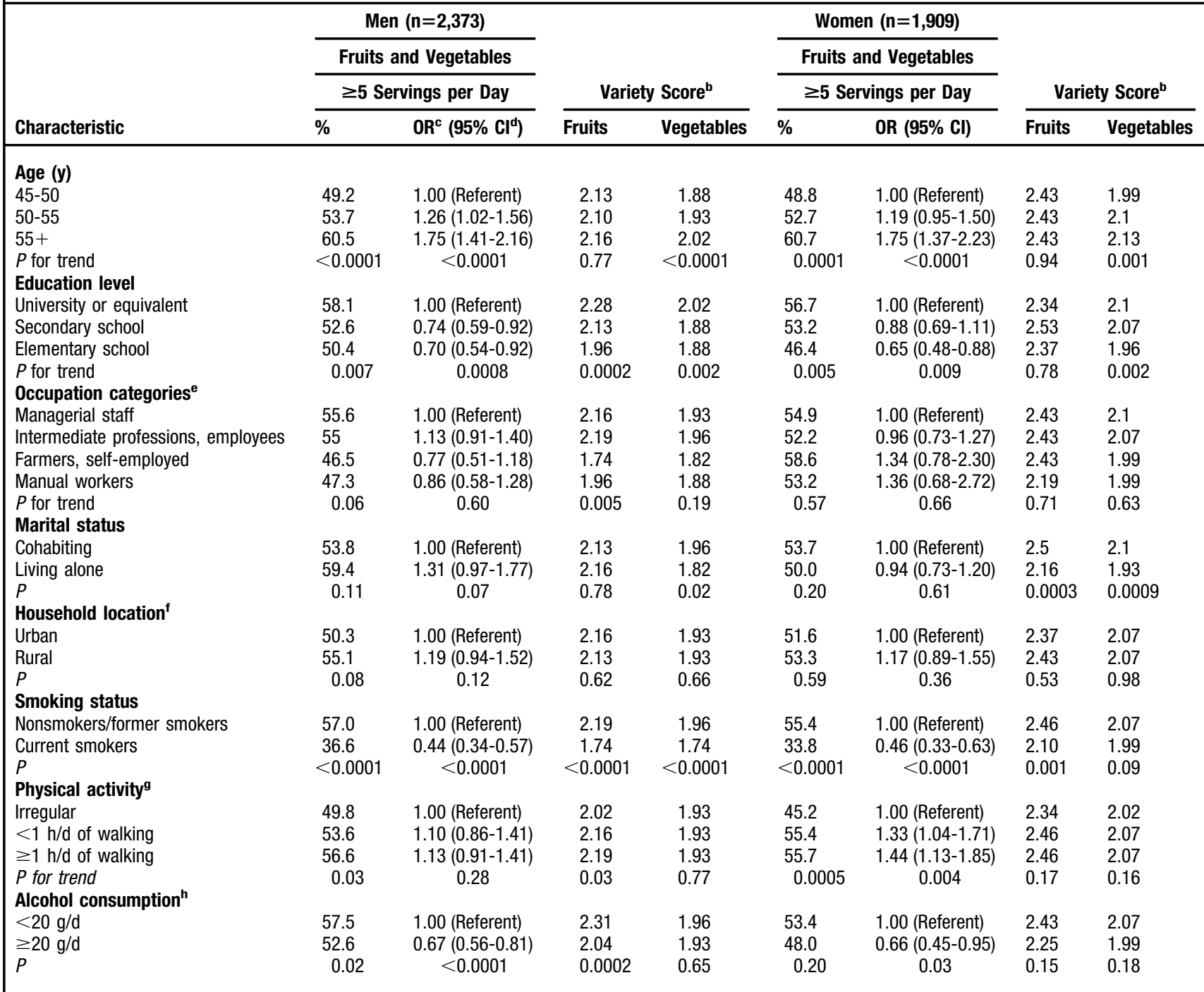

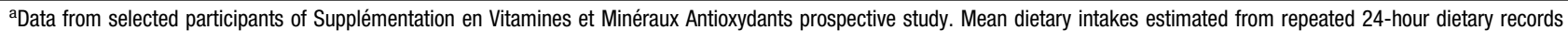
collected during 1995-1997.

bSeparate variety scores were calculated for fruits and vegetables. Methodology used was similar to those described by Giskes and colleagues (17). Variety was measured as the number of different types of fruits/vegetables consumed. Each variety of fruits/vegetables consumed was given a score of 1 . Mixed dishes were given a score of 2 when the recipe contained at least two types of fruits/vegetables.

${ }^{\mathrm{c}} \mathrm{OR}=$ odds ratio. $\mathrm{OR}$ determined by logistic regression analyses. Variables included in the model were age, education level, occupation categories, marital status, household location, smoking status, physical activity categories, alcohol consumption, and total daily energy intakes.

${ }^{\mathrm{d}} \mathrm{Cl}$-confidence interval. $\mathrm{Cl}$ determined by logistic regression analyses. Variables included in the model were age, education level, occupation categories, marital status, household location, smoking status, physical activity categories, alcohol consumption, and total daily energy intakes.

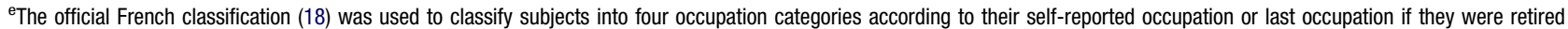
or unemployed. The incomes of these different occupation categories are generally quite close for intermediate professions, employees, farmers, and manual workers and higher for the managerial staff.

'The location of residence was classified in two categories (urban/rural) according to the definition of the French National Institute of Statistics and Economics Studies, which is based on both population density and economic activity.

9The overall level of habitual physical activity was assessed using the following questions: "Do you get regular physical activity (transportation, work, and leisure combined): yes/no? If yes, is it equivalent to at least 1 hour of walking per day?" (20). Responses were coded in three categories.

hAlcohol intake was estimated in grams of alcohol per day, from a short validated semiquantitative dietary questionnaire (21).

with previous literature $(8,10,24)$. However, it has been suggested that relationships with several indicators of socioeconomic status should be addressed simultaneously to provide a better understanding of the social inequalities in dietary habits (25-27). Occupation category is another widely used indicator of socioeconomic status. In 


\begin{tabular}{|c|c|c|c|c|c|c|c|}
\hline \multirow[b]{2}{*}{ Characteristic } & \multirow{2}{*}{$\frac{\text { Total Daily Diet }}{€ / \mathrm{d}^{\mathbf{b}}}$} & \multicolumn{2}{|c|}{ Fruits } & \multicolumn{2}{|c|}{ Vegetables } & \multicolumn{2}{|c|}{ Fruits and Vegetables } \\
\hline & & $€ / d$ & $\%$ & $€ / d$ & $\%$ & $€ / \mathrm{d}$ & $\%$ \\
\hline $\begin{array}{l}\text { Men }(n=2,373) \text {, overall } \\
\text { Education level }^{\mathrm{c}}\end{array}$ & 6.92 & 0.55 & 8.2 & 0.54 & 8.0 & 1.09 & 16.0 \\
\hline University or equivalent & 6.9 & 0.59 & 8.8 & 0.55 & 8.2 & 1.14 & 16.9 \\
\hline Secondary school & 6.97 & 0.54 & 7.9 & 0.53 & 7.8 & 1.07 & 15.7 \\
\hline Elementary school & 6.84 & 0.51 & 7.6 & 0.53 & 7.9 & 1.04 & 15.5 \\
\hline \multicolumn{8}{|l|}{ Occupation categories ${ }^{\text {de }}$} \\
\hline Managerial staff & 7.09 & 0.57 & 8.2 & 0.54 & 7.9 & 1.1 & 16.0 \\
\hline Intermediate professions, employees & 6.8 & 0.56 & 8.4 & 0.53 & 8.0 & 1.09 & 16.4 \\
\hline Farmers, self-employed & 6.66 & 0.49 & 7.5 & 0.53 & 8.1 & 1.01 & 15.6 \\
\hline Manual workers & 6.87 & 0.5 & 7.5 & 0.54 & 8.3 & 1.04 & 15.8 \\
\hline$P$ for trend & 0.0001 & 0.006 & 0.02 & 0.88 & 0.48 & 0.06 & 0.21 \\
\hline $\begin{array}{l}\text { Women }(n=1,909) \text {, overall } \\
\text { Education level }{ }^{\mathrm{c}}\end{array}$ & 5.36 & 0.54 & 10.2 & 0.5 & 9.7 & 1.05 & 19.9 \\
\hline University or equivalent & 5.48 & 0.56 & 10.5 & 0.51 & 9.6 & 1.07 & 20.0 \\
\hline Secondary school & 5.35 & 0.55 & 10.4 & 0.51 & 9.7 & 1.05 & 20.2 \\
\hline Elementary school & 5.19 & 0.5 & 9.7 & 0.49 & 9.7 & 0.99 & 19.4 \\
\hline \multicolumn{8}{|l|}{ Occupation categories ${ }^{\mathrm{de}}$} \\
\hline Managerial staff & 5.56 & 0.51 & 9.6 & 0.5 & 9.3 & 1.01 & 18.9 \\
\hline Intermediate professions, employees & 5.31 & 0.54 & 10.4 & 0.5 & 9.7 & 1.05 & 20.1 \\
\hline Farmers, self-employed & 5.52 & 0.57 & 10.6 & 0.56 & 10.4 & 1.14 & 21.0 \\
\hline Manual workers & 5.14 & 0.55 & 10.6 & 0.51 & 10.0 & 1.06 & 20.6 \\
\hline$P$ for trend & 0.003 & 0.14 & 0.05 & 0.04 & 0.08 & 0.03 & 0.008 \\
\hline \multicolumn{8}{|c|}{$\begin{array}{l}\text { aMean dietary intakes estimated from repeated 24-hour dietary records collected during 1995-1997. } \\
\text { bIncluding beverages. Costs were based on the mean retail prices in France in 1997, obtained from marketing research, from the French National Institute of Statistics and Economic } \\
\text { Studies, and from supermarket Web sites. } 1 €=1.49 \text { US\$ (as of January 2, 2008). } \\
\text { cAdjusted for age, total daily energy intake, and occupation categories. }\end{array}$} \\
\hline
\end{tabular}

our study, occupation was not an independent correlate of fruit and vegetable consumption. Education level reflects other aspects than socioeconomic status, such as dietary knowledge and ability to interpret health education messages $(25,27)$. That may be another explanation of the differential relationships of adherence to the recommendation to consume five servings of fruits and vegetables per day with education level and occupation category.

\section{Sociodemographic and Lifestyle Characteristics and the 5 A Day Recommandation}

Numerous studies have reported inverse associations between fruit and vegetable consumption and other lesshealthful behaviors, including smoking status $(23,28,29)$, alcohol consumption $(30,31)$, and low physical activity level $(30,32)$. The results from our study are in line with previous data, even though in men physical activity level was not related to the adherence of the 5 A Day recommendation. Previous studies have shown that married people have higher fruit and vegetable intakes (9). In our study, being married/living with a partner was weakly inversely associated with meeting fruit and vegetable recommendation in men (borderline significant) and no association was observed in women. No difference in fruit and vegetable consumption was found according to urban/rural location, whereas Johansson and colleagues (33) reported that subjects living in rural areas had lower fruit and vegetable intakes than their counterparts living in cities, even after adjustment for age, sex, and education. However, good local access to food stores and availability of fruit and vegetable may be a more important environmental determinant of fruit and vegetable consumption as suggested by a growing body of literature (9). Moreover, Giskes and colleages (34) recently showed that perceived availability of healthful foods may be a major contributor of food purchasing.

\section{Socioeconomic Status and Fruit and Vegetable Variety}

In addition to encouraging fruit and vegetable consumption, promotion of their variety may be important to ensure sufficient intakes for certain nutrients (35). Only one study has previously examined the differences in fruit or 


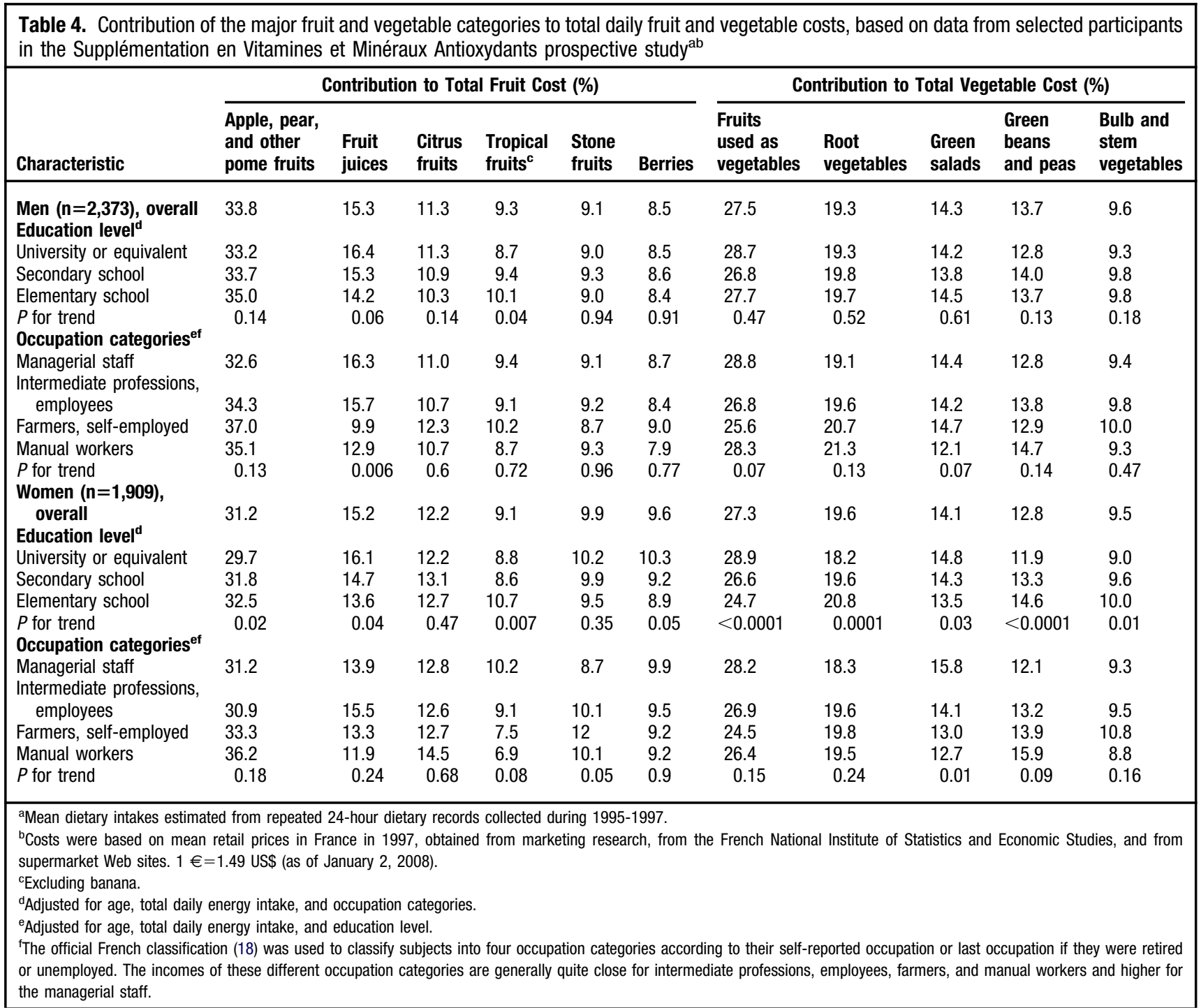

vegetable varieties according to socioeconomic status. Giskes and colleagues reported a lower variety in adults from low-income socioeconomic groups (17). The observed fruit variety score is approximately the same as those found in Australian adults, whereas the variety in vegetables consumed was one point lower in this sample (17). This discrepancy could be related to differences in dietary assessment. In fact, the choice to select at least six 24hour dietary records over a 2-year period allows a more reliable diet estimation and limits misclassification by decreasing intraindividual variation (36). Precision of data from other studies is limited because they used only food frequency questionnaires or one 24-hour dietary recall. Another possibility to this discrepancy is eventually the fruit and vegetable classification used, which was not specified in the article by Giskes and colleagues. However, in accordance with this previous study, a negative relationship of vegetable variety with education level was found in both sexes. In addition, fruit variety was posi- tively associated with both education and occupation categories, but only in men. These results support the hypothesis that economic constraints may be one of the barriers to fruit and vegetable consumption, especially in low-income populations (37). Men from the highest occupation categories had higher total daily diet cost and spent more money to eat fruit and vegetable. In women, diet cost and fruit and vegetable expenses were positively related to education and negatively to occupation. Differences in fruit and vegetable product prices (38) may also explain some differential fruit and vegetable consumption patterns because subjects with a primary school level or having a manual occupation consumed more lowpriced fruit and vegetables, such as pome fruits, fruits used as vegetables and beans/peas. Several studies also suggest that access to food stores and availability and variety of fruit and vegetable may be lower in poorer neighbourhoods (39). In addition to influence of local environment, results from a recently published study showed 
that several dimensions of the social context might also influence fruit and vegetable consumption (40).

Several limitations should be addressed. Because our study was performed in a French context, these results should be compared to data obtained in other populations with caution. More than half of subjects achieved the five servings a day of fruit and vegetables recommendation. Fruit and vegetable consumption seems particularly high compared to other populations $(41,42)$ : In a study based on the 1989-1991 Continuing Surveys of Food Intakes by Individuals, $32 \%$ of US adults older than age 20 years old met the 5 A Day objective (43). In 1999-2000, it has been estimated that only $40 \%$ of Americans ate an average of five or more servings of fruits and vegetables per day (41). However, our study was limited to the age range 45 to 62 years and previous studies have shown that the percentages of subjects meeting the $5 \mathrm{~A}$ Day fruit and vegetable recommendation were lower in younger age groups $(41,44)$. Another limitation is that subjects were participants of a nutrition intervention study (45), thus they may have had more healthful lifestyle and dietary patterns. Another potential limitation is the bias that can be derived from over-reporting consumption among those with higher levels of education (8).

\section{CONCLUSIONS}

In this study of middle-aged French subjects, socioeconomic disparities in both quantity and variety of fruit and vegetable consumed were found. Higher socioeconomic groups also spent more to eat fruit and vegetables. This suggests that price intervention may be a valuable strategy for increasing the proportion of subjects who attain the recommended levels, especially in low-income socioeconomic groups. A reduction in the price of fruit and vegetables, which can be achieved by means of public policies, could lead to an increase in fruit and vegetable intake (46). In addition, for underprivileged people with particularly low income, distribution of fruit and vegetable vouchers (or checks), has been demonstrated as an useful measure to encourage low-income consumers to increase the consumption of such products $(47,48)$. Achieving the recommendation to consume five servings per day of fruit and vegetables was related to education but not to occupation categories, suggesting that factors other than budgetary resources may explain the socioeconomic disparities in fruit and vegetable consumption.

To develop effective interventions and policies, there is a need to better understand the relative influence of budgetary constraints, nutrition knowledge and skills, social context, and environmental barriers. Whatever the country, nutrition education is a practical intervention that can be applied by many health professionals until global policy changes can be accomplished.

The first author (C.E.) was supported in part by the Fondation Louis Bonduelle, France.

The authors thank Stacie Chat-Yung for reviewing and editing the manuscript.

\section{References}

1. Agudo A, Cabrera L, Amiano P, Ardanaz E, Barricarte A, Berenguer T, Chirlaque MD, Dorronsoro M, Jakszyn P, Larranaga N, Martinez
C, Navarro C, Quiros JR, Sanchez MJ, Tormo MJ, Gonzalez CA. Fruit and vegetable intakes, dietary antioxidant nutrients, and total mortality in Spanish adults: Findings from the Spanish cohort of the European Prospective Investigation into Cancer and Nutrition (EPIC-Spain). Am J Clin Nutr. 2007;85:1634-1642.

2. Dauchet L, Amouyel P, Hercberg S, Dallongeville J. Fruit and vegetable consumption and risk of coronary heart disease: A meta-analysis of cohort studies. J Nutr. 2006;136:2588-2593.

3. He FJ, Nowson CA, MacGregor GA. Fruit and vegetable consumption and stroke: Meta-analysis of cohort studies. Lancet. 2006;367:320326.

4. International Agency for Research on Cancer. IARC Handbooks of Cancer Prevention. Vol 8: Fruits and Vegetables. Lyon, France: IARC Press; 2003.

5. Diet, Nutrition, and the Prevention of Chronic Diseases. Geneva, Switzerland: World Health Organization; 2003. Technical Report Series No. 916.

6. Hercberg S, Chat-Young S, Chauliac M. The French National Nutrition and Health Program: 2001-2006-2010. Int J Public Health. 2008; 53:68-77.

7. Beer-Borst S, Hercberg S, Morabia A, Bernstein MS, Galan P, Galasso R, Giampaoli S, McCrum E, Panico S, Preziosi P, Ribas L, SerraMajem L, Vescio MF, Vitek O, Yarnell J, Northridge ME. Dietary patterns in six european populations: Results from EURALIM, a collaborative European data harmonization and information campaign. Eur J Clin Nutr. 2000;54:253-262.

8. Irala-Estevez JD, Groth M, Johansson L, Oltersdorf U, Prattala R, Martinez-Gonzalez MA. A systematic review of socio-economic differences in food habits in Europe: Consumption of fruit and vegetables. Eur J Clin Nutr. 2000;54:706-714.

9. Kamphuis CB, Giskes K, de Bruijn GJ, Wendel-Vos W, Brug J, van Lenthe FJ. Environmental determinants of fruit and vegetable consumption among adults: A systematic review. Br J Nutr. 2006;96:620635.

10. Roos G, Johansson L, Kasmel A, Klumbiene J, Prattala R. Disparities in vegetable and fruit consumption: European cases from the north to the south. Public Health Nutr. 2001;4:35-43.

11. Hercberg S, Preziosi P, Briancon S, Galan P, Triol I, Malvy D, Roussel AM, Favier A. A primary prevention trial using nutritional doses of antioxidant vitamins and minerals in cardiovascular diseases and cancers in a general population: The SU.VI.MAX study-Design, methods, and participant characteristics. SUpplementation en VItamines et Mineraux AntioXydants. Control Clin Trials. 1998;19:336-351.

12. Capita R, Alonso-Calleja C. Differences in reported winter and summer dietary intakes in young adults in Spain. Int J Food Sci Nutr. 2005;56:431-443.

13. Le Moullec N, Deheeger M, Preziosi P, Montero P, Valeix P, RollandCachera M-F, Potier de Courcy G, Christides J-P, Galan P, Hercberg $\mathrm{S}$. Validation du manuel-photos utilisé pour l'enquête alimentaire de l'étude SU.VI.MAX \{Validation of photographic document used to estimate the amounts of foods eaten by subjects in the SU.VI.MAX study]. Cah Nutr Diet. 1996;31:158-164.

14. Hercberg $\mathrm{S}$, ed. Table de composition des aliments SU.VI.MAX [French food composition databank from the SU.VI.MAX study]. Paris, France: Economica; 2005.

15. Williams C. Healthy eating: Clarifying advice about fruit and vegetables. BMJ. 1995;310:1453-1455.

16. World Cancer Research Fund/American Institute for Cancer Research. Food, Nutrition, Physical Activity, and the Prevention of Cancer: A Global Perspective. Washington DC: American Institute for Cancer Research; 2007.

17. Giskes K, Turrell G, Patterson C, Newman B. Socio-economic differences in fruit and vegetable consumption among Australian adolescents and adults. Public Health Nutr. 2002;5:663-669.

18. Les nomenclatures des professions et catégories socioprofessionnelles [Lexicon for occupational categories]. National Institute for Statistics and Economic Studies Web site. http://www.insee.fr/fr/nom_def_met/ nomenclatures/pcs.htm. Accessed May 5, 2008.

19. Le Jeannic T, Vidalenc J. Pôles urbains et périurbanisation, le zonage en aires urbaines [Urban and peri-urban zoning]. Paris, France: INSEE Première; 1997.

20. Czernichow S, Bertrais S, Preziosi P, Galan P, Hercberg S, Oppert JM. Indicators of abdominal adiposity in middle-aged participants of the SU.VI. MAX study: Relationships with educational level, smoking status and physical inactivity. Diabetes Metab. 2004;30:153-159.

21. Lasfargues G, Vol S, Le Clesiau H, Bedouet M, Hagel L, Constans T, Tichet J. [Validity of a short self-administered dietary questionnaire compared with a dietetic interview]. Presse Med. 1990;19:953-957.

22. O’Brien MM, Kiely M, Galvin M, Flynn A. The importance of compos- 
ite foods for estimates of vegetable and fruit intakes. Public Health Nutr. 2003;6:711-726.

23. Billson H, Pryer JA, Nichols R. Variation in fruit and vegetable consumption among adults in Britain. An analysis from the dietary and nutritional survey of British adults. Eur J Clin Nutr. 1999;53: 946-952.

24. Perrin AE, Simon C, Hedelin G, Arveiler D, Schaffer P, Schlienger JL. Ten-year trends of dietary intake in a middle-aged French population: Relationship with educational level. Eur J Clin Nutr. 2002;56:393401.

25. Galobardes B, Morabia A, Bernstein MS. Diet and socioeconomic position: does the use of different indicators matter? Int $J$ Epidemiol. 2001;30:334-340.

26. Lallukka T, Laaksonen M, Rahkonen O, Roos E, Lahelma E. Multiple socio-economic circumstances and healthy food habits. Eur J Clin Nutr. 2007;61:701-710.

27. Turrell G, Hewitt B, Patterson C, Oldenburg B. Measuring socioeconomic position in dietary research: Is choice of socio-economic indicator important? Public Health Nutr. 2003;6:191-200.

28. Birkett NJ. Intake of fruits and vegetables in smokers. Public Health Nutr. 1999;2:217-222.

29. Pollard J, Greenwood D, Kirk S, Cade J. Motivations for fruit and vegetable consumption in the UK Women's Cohort Study. Public Health Nutr. 2002;5:479-486.

30. Agudo A, Pera G. Vegetable and fruit consumption associated with anthropometric, dietary, and lifestyle factors in Spain. EPIC Group of Spain. European Prospective Investigation into Cancer. Public Health Nut. 1999;2:263-271.

31. Padrao P, Lunet N, Santos AC, Barros H. Smoking, alcohol, and dietary choices: Evidence from the Portuguese National Health Survey. BMC Public Health. 2007;7:138.

32. Oppert JM, Thomas F, Charles MA, Benetos A, Basdevant A, Simon C. Leisure-time and occupational physical activity in relation to cardiovascular risk factors and eating habits in French adults. Public Health Nutr. 2006;9:746-754.

33. Johansson L, Thelle DS, Solvoll K, Bjorneboe GE, Drevon CA Healthy dietary habits in relation to social determinants and lifestyle factors. Br J Nutr. 1999;81:211-220.

34. Giskes K, van Lenthe FJ, Brug J, Mackenbach JP, Turrell G. Socioeconomic inequalities in food purchasing: The contribution of respondent-perceived and actual (objectively measured) price and availability of foods. Prev Med. 2007;45:41-48.

35. Giskes K, Turrell G, Patterson C, Newman B. Socioeconomic differences among Australian adults in consumption of fruit and vegetables and intakes of vitamins A, C and folate. J Hum Nutr Diet. 2002;15: 375-385

36. Sempos CT, Johnson NE, Smith EL, Gilligan C. Effects of intraindi- vidual and interindividual variation in repeated dietary records. Am J Epidemiol. 1985;121:120-130.

37. Drewnowski A, Darmon N. Food choices and diet costs: An economic analysis. J Nutr. 2005;135:900-904.

38. Maillot M, Darmon N, Drewnowski A, Arnault N, Hercberg S. Le coût et la qualité nutritionnelle des groupes d'aliments: quelle hiérarchie? [Food groups: Which hierarchy in terms of nutritional quality and cost?] Cah Nutr Diet. 2006;41:87-96.

39. Morland K, Wing S, Diez RA. The contextual effect of the local food environment on residents' diets: The atherosclerosis risk in communities study. Am J Public Health. 2002;92:1761-1767.

40. Sorensen G, Stoddard AM, Dubowitz T, Barbeau EM, Bigby J, Emmons KM, Berkman LF, Peterson KE. The influence of social context on changes in fruit and vegetable consumption: Results of the healthy directions studies. Am J Public Health. 2007;97:1216-1227.

41. Guenther PM, Dodd KW, Reedy J, Krebs-Smith SM. Most Americans eat much less than recommended amounts of fruits and vegetables. J Am Diet Assoc. 2006;106:1371-1379.

42. Naska A, Vasdekis VG, Trichopoulou A, Friel S, Leonhauser IU, Moreiras O, Nelson M, Remaut AM, Schmitt A, Sekula W, Trygg KU, Zajkas G. Fruit and vegetable availability among 10 European countries: How does it compare with the '5-A-Day' recommendation? DAFNE I and II projects of the European Commission. $\mathrm{Br} J \mathrm{Nutr}$. 2000;84:549-556.

43. Krebs-Smith SM, Cook A, Subar AF, Cleveland L, Friday J. US adults' fruit and vegetable intakes, 1989 to 1991: A revised baseline for the Healthy People 2000 objective. Am J Public Health. 1995;85: 1623-1629.

44. Agudo A, Amiano P, Barcos A, Barricarte A, Beguiristain JM, Chirlaque MD, Dorronsoro M, Gonzalez CA, Lasheras C, Martinez C, Navarro C, Pera G, Quiros JR, Rodriguez M, Tormo MJ. Dietary intake of vegetables and fruits among adults in five regions of Spain. EPIC Group of Spain. European Prospective Investigation into Cancer and Nutrition. Eur J Clin Nutr. 1999;53:174-180.

45. Hercberg S, Galan P, Preziosi P, Bertrais S, Mennen L, Malvy D, Rouseel AM, Favier A, Briançon S. The SU.VI.MAX Study: A randomized, placebo-controlled trial of the health effects of antioxidant vitamins and minerals. Arch Intern Med. 2004;164:2335-2342.

46. Claro RM, Carmo HC, Machado FM, Monteiro CA. Income, food prices, and participation of fruit and vegetables in the diet. Rev Saude Publica. 2007;41:557-564.

47. Anderson JV, Bybee DI, Brown RM, McLean DF, Garcia EM, Breer ML, Schillo BA. 5 A Day fruit and vegetable intervention improves consumption in a low income population. J Am Diet Assoc. 2001;101: 195-202.

48. Herman DR, Harrison GG, Jenks E. Choices made by low-income women provided with an economic supplement for fresh fruit and vegetable purchase. J Am Diet Assoc. 2006;106:740-744. 